Original Research

\title{
Kinetic Asymmetry During a Repetitive Tuck Jump Task in Athletes with a History of Anterior Cruciate Ligament Reconstruction
}

\author{
Adam W. VanZile1, Matthew J. Snyder², Emily A. Watkins ${ }^{3}$, Jithmie Jayawickrema ${ }^{4}$, Tricia L. Widenhoefer ${ }^{5}$, Thomas G. \\ Almonroeder ${ }^{6}$ \\ 1 Optimum Performance Therapy, ${ }^{2}$ Department of Sports Medicine, Fort Wayne Orthopedics, ${ }^{3}$ Department of Exercise Science, Trine University, 4 \\ Parkview TherapyONE, 5 Physical Therapy Program, Trine University, ${ }^{6}$ Department of Health Professions, University of Wisconsin-LaCrosse (WI) \\ Keywords: sports medicine, rehabilitation, plyometrics, force, biomechanics \\ https://doi.org/10.26603/001c.28088
}

\section{International Journal of Sports Physical Therapy}

Vol. 16, Issue 5, 2021

\begin{abstract}
Background
Athletes who have undergone anterior cruciate ligament reconstruction typically exhibit relatively high/rapid loading of their uninvolved limb during bilateral landing and jumping (vs. their limb that underwent reconstruction), which may place their uninvolved limb at risk for injury. However, previous studies have only examined forces and loading rates for tasks involving an isolated land-and-jump.
\end{abstract}

\section{Purpose}

The purpose of this study was to examine bilateral landing and jumping kinetics during performance of a repetitive tuck jump task in athletes who had undergone anterior cruciate ligament reconstruction and completed rehabilitation.

\section{Study Design}

Cross-sectional study

\section{Methods}

Nine athletes (four males, five females) participated in this study. All participants had undergone successful unilateral anterior cruciate ligament reconstruction, had completed post-operative rehabilitation, and were in the process of completing return-to-sport testing. Athletes performed a repetitive tuck jump task for 10 seconds, while ground reaction forces were recorded for their uninvolved and involved limbs via separate force platforms. Two-way analysis of variance, for within-subjects factors of limb and cycle, was performed for the impact forces, loading rates, and propulsive forces from the first five land-and-jump cycles completed.

\section{Results}

There was not a limb-by-cycle interaction effect or main effect of cycle for the impact forces, loading rates, or propulsive forces; however, there was a main effect of limb for the impact forces $(\mathrm{F}(1,8)=14.64 ; \mathrm{p}=0.005)$, loading rates $(\mathrm{F}(1,8)=5.60 ; \mathrm{p}=0.046)$, and propulsive forces $(\mathrm{F}(1,8)=10.38 ; \mathrm{p}=0.012)$. Impact forces, loading rates, and propulsive forces were higher for the uninvolved limb, compared to the involved limb, over the five land-and-jump cycles analyzed.

\footnotetext{
a Corresponding author:

Thomas G. Almonroeder, DPT, PhD

Assistant Professor

Department of Health Professions

University of Wisconsin - La Crosse

1300 Badger Street, 54601, La Crosse, WI, USA

E-mail: talmonroeder@uwlax.edu

Phone: 608-785-8475

Fax: 608-785-8460
} 


\section{Conclusion}

The athletes in this study consistently applied higher and more rapid loads to their uninvolved limb over multiple land-and-jump cycles. This may help to explain the relatively high injury rates for the uninvolved limb in athletes who have returned to sport following anterior cruciate ligament reconstruction.

\section{INTRODUCTION}

Anterior cruciate ligament (ACL) tears are common among young athletes who compete in sports that involved frequent landing and jumping, such as basketball. ${ }^{1}$ Surgical reconstruction of the ACL is commonly recommended for athletes who plan to resume sports participation. ${ }^{2}$ Unfortunately, athletes who have undergone ACL reconstruction are at relatively high risk for sustaining another ACL injury after returning to sport (compared to athletes without a history of ACL injury). ${ }^{3}$ In most cases the second ACL injury occurs during the first year following return to sport and involves the athlete's previously uninjured limb (i.e. contralateral to the limb that underwent ACL reconstruction). ${ }^{4}$ It appears there is an urgent need to identify factors that contribute to secondary risk of ACL injury (uninjured limb) in athletes who return to sport following ACL reconstruction.

Athletes often exhibit inter-limb asymmetries in limb loading during bilateral landing and jumping, even after they have completed rehabilitation and returned to sport. ${ }^{5-11}$ Typically, athletes apply higher and more rapid loads to their uninvolved limb during landing and jumping, compared to their ACL-reconstructed limb. For example, Paterno et al. ${ }^{7}$ examined vertical ground reaction forces during performance of a drop vertical jump task in a group of 14 athletes who had undergone ACL reconstruction, completed rehabilitation, and been cleared to return to sport by their physician and physical therapist, and found that the athletes in their study demonstrated higher peak vertical ground reaction forces for their uninvolved limbs (vs. their involved limbs) during the initial landing phase of the drop vertical jump (impact forces) and immediately prior to takeoff (propulsive forces). In addition, they also demonstrated higher loading rates for their uninvolved limbs during landing. These inter-limb kinetic asymmetries may help to explain why ACL injuries are common for the uninvolved limb in athletes who have undergone ACL reconstruction, as relatively high/rapid impact forces contribute to a movement pattern that strains the ACL ${ }^{12}$ and may increase ACL injury risk. ${ }^{13,14}$

While previous authors have found that athletes who have undergone ACL reconstruction tend to exhibit higher and more rapid loading of their uninvolved limb during bilateral landing and jumping, these studies have only included tasks that involve a single land-and-jump. As a result, it is unclear whether inter-limb asymmetry in limb loading changes as athletes complete multiple land-andjump cycles. This is important to examine since athletes must often perform a series of landing-and-jumping cycles in short succession during competition. For instance, a basketball player pursuing a rebound may need to land and quickly jump, repeatedly. Athletes also often complete multiple land-and-jump cycles during plyometric training (e.g. repeated tuck jumps). ${ }^{15,16}$ In addition, previous studies have not examined symmetry in foot initial contact timing during performance of a repetitive jump-landing task. Examining foot initial contact timing could provide additional insight, since the limbs are loaded very rapidly during landing, and therefore, even subtle asymmetries in initial contact timing could contribute to an overreliance on one limb for support. ${ }^{16}$

The purpose of this study was to examine bilateral landing and jumping kinetics during performance of a repetitive tuck jump task in athletes who had undergone ACL reconstruction and completed rehabilitation. It was hypothesized that athletes would demonstrate higher impact forces, loading rates, and propulsive forces for their uninvolved limb, compared to their involved limb, for each land-and-jump cycle analyzed. No a priori hypotheses were proposed regarding how the degree of inter-limb asymmetry would change as athletes completed successive land-and-jump cycles, since previous studies have not examined changes in limb loading across multiple jump-landings. A secondary purpose of this study was to examine foot initial contact timing during performance of the repetitive tuck jump task, as this could provide additional insight into why athletes who have undergone ACL reconstruction tend to exhibit greater loading of their uninjured limb during landing.

\section{METHODS}

Nine athletes (four males, five females) participated in this cross-sectional study. All data were collected during the athlete's return to sport testing session, which took place at the Academy of Sports and Health Centre (Fort Wayne, IN, USA). Athletes were eligible to participate if they were between 14-25 years of age, had undergone successful unilateral primary ACL reconstruction within the previous 18 months, intended to return to a sport that involved landing/ jumping, had completed conventional post-operative rehabilitation, and had been cleared by their physician and physical therapist to resume landing and jumping activities. Athletes who were 14-25 years of age were selected for this study because this appears to be the age range where most ACL injuries occur ${ }^{17}$ and the risk of a second ACL injury appears to be particularly high in athletes 25 years of age or younger. ${ }^{3}$ Athletes were excluded from participating if they had a history of surgery or significant injury involving their uninvolved limb. All athletes had isolated ACL injuries, with no other concomitant injuries. The mean $( \pm$ standard deviation) age, mass, and height of the athletes were $16.9 \pm 1.8$ years, $70.3 \pm 12.4 \mathrm{~kg}$, and $1.8 \pm 0.1 \mathrm{~m}$. The median (range) number of days since their ACL reconstruction surgery was 175 days (152-223 days). Six athletes had received bone-patellar tendon-bone autografts and three had received hamstrings tendon autografts. Five athletes reported that they had injured their dominant limb, while 
four athletes reported that they had injured their non-dominant limb. For the purpose of this study, the dominant limb was defined as the leg the athletes reported that they would have used to kick a ball for maximal distance prior to their injury. This study protocol was approved by the Institutional Review Board at Lutheran Hospital (Fort Wayne, IN, USA). All athletes provided informed consent/assent prior to enrollment and informed consent was obtained from a parent or guardian for athletes who were younger than 18 years of age.

Athletes completed the Sport and Recreation subscale of the Knee Injury and Osteoarthritis Outcome Score (KOOS) questionnaire prior to testing. ${ }^{18}$ The Sport and Recreation subscale of the KOOS asks individuals to rate their perceived level of difficulty with squatting, running, jumping, twisting/pivoting, and kneeling on a Likert scale (none, mild, moderate, severe, extreme) and values are transformed into a percentage where $0 \%$ represents extreme difficulty and $100 \%$ represents no deficits in knee-related function. The Sport and Recreation subscale of the KOOS has been shown to demonstrate good test-retest reliability in individuals with a history of ACL injury (intraclass correlation coefficient $=0.81$ ) and is responsive to changes in knee-related function following ACL reconstruction. ${ }^{18}$ This self-reported measure was recorded in order to describe the athletes' perceived level of knee-related function.

Next, athletes completed a standardized warm-up that included various landing and jumping tasks. They then completed the repetitive tuck jump task described by Myer et al. ${ }^{16}$ Athletes started in a standing position with their feet on separate, adjacent force platforms (AccuPower, Advanced Mechanical Technology, Inc., Watertown, MA, USA) (Figure 1). They initiated the tuck jump task by performing a rapid countermovement, jumped vertically bringing their knees upward until their thighs were parallel to the ground (tuck jump), and then landed on both limbs. Upon landing, they immediately performed the next tuck jump as quickly as possible. The athletes continued to perform tuck jumps for 10 seconds. The force platforms simultaneously recorded three-dimensional ground reaction forces at a sampling rate of $600 \mathrm{~Hz}$ throughout performance of the repetitive tuck jump task. Athletes were encouraged to focus on jumping vertically during the task so that their feet continued to contact the same force platforms. An investigator monitored the locations of the athletes' feet during the landings and noted when an athlete's foot did not appear to land completely within the respective force platform. Each athlete was given a demonstration and performed a limited practice trial prior to testing.

Ground reaction force data were filtered using a 4th order, zero lag, low-pass Butterworth filter with a cutoff frequency of $50 \mathrm{~Hz}$ and normalized to body weight (BW). ${ }^{7}$ The peak vertical ground reaction forces (impact forces) and loading rates during the initial $25 \%$ of stance and the peak vertical ground reaction forces during last $25 \%$ of stance (propulsive forces) were identified from the time series associated with each force platform during the first five landand-jump cycles of the repetitive tuck jump task (Figure 1). All athletes successfully landed with their feet on separate force platforms for the first five land-and-jump cycles. Additional land-and-jump cycles beyond the first five were not
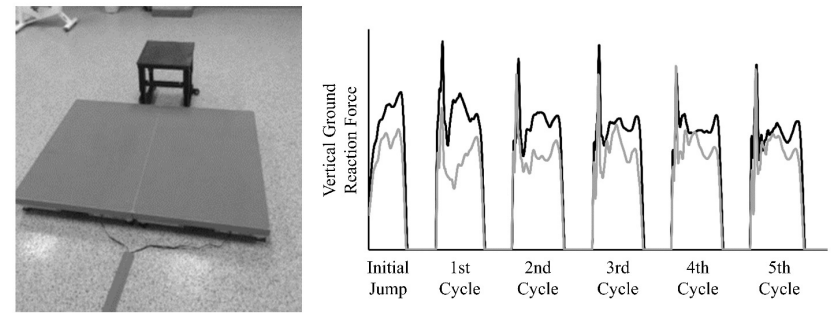

\section{Figure 1.}

Left panel - picture of the dual force platform setup. Right panel - example of one athlete's vertical ground reaction force time series during performance of the repetitive tuck jump task (uninjured limb = black time series; injured limb $=$ grey time series).

examined since many athletes failed to continue to land with their feet on separate force platforms. The stance phase was defined as the total time when the vertical ground reaction force exceeded a threshold of $10 \mathrm{~N}$ (i.e. initial contact to takeoff). Loading rates were calculated by dividing the impact forces by the time from initial contact until the impact force (BW/s). ${ }^{7}$ Inter-limb symmetry indices were also calculated for the impact forces, loading rates, and propulsive forces for each land-and-jump cycle by dividing the values for the involved limb by those of the uninvolved limb, and multiplying by $100 .^{8}$ As a result, inter-limb symmetry index values less than $100 \%$ reflect lower or less rapid loading of the involved limb.

In order to examine initial contact timing during the landings, the first frame where the vertical ground reaction force exceeded $10 \mathrm{~N}$ (initial contact) and remained greater than $10 \mathrm{~N}$ for at least 50 frames was identified. The difference between the initial contact frames for each limb (uninvolved, involved) was then converted to milliseconds (ms) based on the sampling rate of the force platforms. ${ }^{19,20}$ Calculations were performed so that positive values represented earlier initial contact for the uninvolved limb, negative values represented earlier initial contact for the involved limb, and zero values represented simultaneous initial contact. Unfiltered ground reaction force data were used for examining the initial contact timing, ${ }^{19}$ since filtering can result in inaccurate temporal events, especially when there is a rapid change in signal amplitude. ${ }^{21}$ All data processing was completed using custom MATLAB scripts (MathWorks Inc., Natick, MA, USA).

\section{STATISTICAL ANALYSIS}

Two-way analysis of variance for within-subjects factors of 'limb' (uninvolved, involved) and 'cycle' (1st, 2nd, 3rd, 4th, th land-and-jump cycle) were performed for the impact forces, loading rates, and propulsive forces. Main effects of limb and cycle were examined when there was not a significant limb-by-cycle interaction effect. A repeated measures analysis of variance, for a within-subjects factor of cycle, was conducted to examine initial contact timing differences among the landings. An alpha of .05 was used for all statistical tests. SPSS software was used for statistical analysis (Version 27; IBM Corp., Armonk, NY, USA). 95\% confidence intervals $(95 \% \mathrm{CI})$ were calculated for the initial contact 
Table 1. Impact forces, loading rates, and propulsive forces for the uninvolved limb (Uninv) and ACLreconstructed (involved) limb (ACLR) for the first five land-and-jump cycles of the repetitive tuck jump task.

\begin{tabular}{|c|c|c|c|c|c|c|c|c|c|c|}
\hline & \multicolumn{2}{|c|}{ 1st Cycle } & \multicolumn{2}{|c|}{ 2nd Cycle } & \multicolumn{2}{|c|}{ 3rd Cycle } & \multicolumn{2}{|c|}{ 4th Cycle } & \multicolumn{2}{|c|}{ 5th Cycle } \\
\hline & Uninv & ACLR & Uninv & ACLR & Uninv & ACLR & Uninv & ACLR & Uninv & ACLR \\
\hline $\begin{array}{l}\text { Impact } \\
\text { Forces } \\
\text { (BW) }\end{array}$ & $\begin{array}{c}1.98 \\
\pm 0.41\end{array}$ & $\begin{array}{r}1.55 \\
\pm 0.25\end{array}$ & $\begin{array}{c}2.17 \\
\pm 0.63\end{array}$ & $\begin{array}{c}1.53 \\
\pm 0.34\end{array}$ & $\begin{array}{c}2.07 \\
\pm 0.50\end{array}$ & $\begin{array}{r}1.69 \\
\pm 0.35\end{array}$ & $\begin{array}{c}2.13 \\
\pm 0.62\end{array}$ & $\begin{array}{c}1.65 \\
\pm 0.37\end{array}$ & $\begin{array}{c}1.95 \\
\pm 0.40\end{array}$ & $\begin{array}{c}1.68 \\
\pm 0.39\end{array}$ \\
\hline $\begin{array}{l}\text { Loading } \\
\text { Rates } \\
\text { (BW/s) }\end{array}$ & $\begin{array}{l}29.61 \\
\pm 9.17\end{array}$ & $\begin{array}{l}22.98 \\
\pm 7.40\end{array}$ & $\begin{array}{c}33.74 \\
\pm 12.92\end{array}$ & $\begin{array}{l}23.91 \\
\pm 7.45\end{array}$ & $\begin{array}{c}31.47 \\
\pm 11.86\end{array}$ & $\begin{array}{l}26.25 \\
\pm 7.44\end{array}$ & $\begin{array}{c}32.00 \\
\pm 12.38\end{array}$ & $\begin{array}{c}28.76 \\
\pm 12.17\end{array}$ & $\begin{array}{c}28.89 \\
\pm 10.34\end{array}$ & $\begin{array}{r}27.34 \\
\pm 14.44\end{array}$ \\
\hline $\begin{array}{l}\text { Propulsive } \\
\text { Forces } \\
\text { (BW) }\end{array}$ & $\begin{array}{c}2.01 \\
\pm 0.72\end{array}$ & $\begin{array}{c}1.63 \\
\pm 0.58\end{array}$ & $\begin{array}{c}2.05 \\
\pm 0.85\end{array}$ & $\begin{array}{c}1.63 \\
\pm 0.62\end{array}$ & $\begin{array}{c}1.88 \\
\pm 0.75\end{array}$ & $\begin{array}{c}1.70 \\
\pm 0.64\end{array}$ & $\begin{array}{c}2.10 \\
\pm 0.87\end{array}$ & $\begin{array}{c}1.68 \\
\pm 0.56\end{array}$ & $\begin{array}{c}2.01 \\
\pm 0.75\end{array}$ & $\begin{array}{c}1.79 \\
\pm 0.78\end{array}$ \\
\hline
\end{tabular}

Mean \pm standard deviation impact forces, loading rates, and propulsive forces for each landing. Uninv = uninvolved limb; ACLR = ACL-reconstructed (involved) limb; BW = bodyweight; $\mathrm{BW} / \mathrm{s}=$ bodyweight $/$ second

Table 2. Impact force, loading rate, and propulsive force inter-limb symmetry indices for the first five land-andjump cycles of the repetitive tuck jump task.

\begin{tabular}{|l|c|c|c|c|c|}
\hline & 1st Cycle & 2nd Cycle & 3rd Cycle & 4th Cycle & 5th Cycle \\
\hline $\begin{array}{l}\text { Impact Force Inter-Limb Symmetry Index } \\
\text { (\%) }\end{array}$ & $\begin{array}{c}80.10 \\
\pm 14.56\end{array}$ & $\begin{array}{c}76.52 \\
\pm 28.28\end{array}$ & $\begin{array}{c}83.60 \\
\pm 15.89\end{array}$ & $\begin{array}{c}80.91 \\
\pm 19.76\end{array}$ & $\begin{array}{c}86.81 \\
\pm 11.81\end{array}$ \\
\hline Loading Rate Inter-Limb Symmetry Index & 79.00 & 79.41 & 88.96 & 96.00 & 93.32 \\
(\%) & \pm 14.25 & \pm 36.01 & \pm 20.70 & \pm 38.11 & \pm 25.72 \\
\hline $\begin{array}{l}\text { Propulsive Forces Inter-Limb Symmetry } \\
\text { Index (\%) }\end{array}$ & 81.60 & 83.83 & 94.04 & 83.91 & 88.03 \\
& \pm 9.40 & \pm 20.25 & \pm 24.67 & \pm 13.77 & \pm 12.08 \\
\hline
\end{tabular}

Mean \pm standard deviation impact force, loading rate, and propulsive force inter-limb symmetry indices for each land-and-jump cycle analyzed. Symmetry index values less than $100 \%$ reflect higher or more rapid loading of the uninvolved limb, compared to the involved limb.

Table 3. Initial contact timing differences for the first five landings of the repetitive tuck jump task.

\begin{tabular}{|c|c|c|c|c|c|}
\hline & 1st Cycle & 2nd Cycle & 3rd Cycle & 4th Cycle & 5th Cycle \\
\hline Time (ms) & $\begin{array}{c}4.4 \pm 7.5 \\
(-1.4,10.2)\end{array}$ & $\begin{array}{c}5.0 \pm 12.1 \\
(-4.3,14.3)\end{array}$ & $\begin{array}{c}6.5 \pm 14.2 \\
(-4.4,17.4)\end{array}$ & $\begin{array}{c}6.1 \pm 16.0 \\
(-6.2,18.4)\end{array}$ & $\begin{array}{c}5.6 \pm 14.7 \\
(-5.7,16.9)\end{array}$ \\
\hline
\end{tabular}

Mean \pm standard deviation and 95\% confidence interval (lower bound, upper bound) for the initial contact timing differences for each landing analyzed. Positive values indicate that the uninvolved limb made contact prior to the involved limb. $\mathrm{ms}=$ milliseconds.

timing differences.

\section{RESULTS}

The mean (range) score on the Sport and Recreation subscale of the KOOS questionnaire was $90.0 \%$ (80-100\%).

For the impact forces, there was not a limb-by-cycle interaction effect $(\mathrm{F}(4,32)=1.14 ; \mathrm{p}=0.355)$ or main effect of cycle $(\mathrm{F}(4,32)=0.45 ; \mathrm{p}=0.770)$; however, there was a main effect of limb $(F(1,8)=14.64 ; p=0.005)$. Impact forces were higher for the uninvolved limb across all five landings analyzed (Tables 1 \& 2).

For the loading rates, there was not a limb-by-cycle interaction effect $(\mathrm{F}(4,32)=1.60 ; \mathrm{p}=0.198)$ or main effect of cycle $(F(4,32)=0.86 ; p=0.501)$; however, there was a main effect of $\operatorname{limb}(F(1,8)=5.60 ; p=0.046)$. Loading rates were higher for the uninvolved limb across all five landings analyzed (Tables 1 \& 2).

For the propulsive forces, there was not a limb-by-cycle interaction effect $(\mathrm{F}(4,32)=1.02 ; \mathrm{p}=0.412)$ or main effect of cycle $(\mathrm{F}(4,32)=0.35 ; \mathrm{p}=0.839)$; however, there was a main effect of limb $(F(1,8)=10.38 ; p=0.012)$. Propulsive forces were higher for the uninvolved limb across all five landand-jump cycles analyzed (Tables 1 \& 2).

The repeated measures analysis of variance indicated that there was no difference in initial contact timing among the five landings $(\mathrm{F}(4,32)=0.062 ; \mathrm{p}=0.993)$ ( $\underline{\text { Table } 3})$. 


\section{DISCUSSION}

The primary purpose of this study was to examine bilateral landing and jumping kinetics during performance of a repetitive tuck jump task in athletes who had undergone ACL reconstruction and completed rehabilitation. As hypothesized, athletes demonstrated higher impact forces, loading rates, and propulsive forces for their uninvolved limb, compared to their involved limb, for each land-andjump cycle analyzed (main effects of limb). The degree of inter-limb kinetic asymmetry did not change significantly across the five land-and-jump cycles (no limb-by-cycle interaction effects). As a result, it appears that the athletes maintained a fairly consistent level of inter-limb kinetic asymmetry when performing the repetitive tuck jump task. The results of this study build on those of earlier studies $^{5-11}$ that have identified persistent inter-limb kinetic asymmetry during performance of tasks involving a single land-and-jump in athletes who have undergone ACL reconstruction and may help to explain why ACL injuries are common for the uninvolved limb in athletes who return to sport following ACL reconstruction.

The athletes in this study exhibited inter-limb impact force differences ranging from 14.6-34.7\% for the five successive land-and-jump cycles analyzed. In each instance, impact forces were greater for the uninvolved limb. This finding that athletes tend to offload their involved limb is consistent with previous studies that have examined isolated, double-leg landings in athletes post-ACL reconstruction. ${ }^{5-11}$ Inter-limb symmetry in loading rates and propulsive forces have been less frequently examined in athletes who have undergone ACL reconstruction. However, Paterno et al. ${ }^{7}$ reported that loading rates during the landing phase of a drop vertical jump were $45.4 \%$ higher for the uninvolved limb, compared to the involved limb, in a group of athletes who had undergone ACL reconstruction and been cleared to return to sport. In addition, they also reported that propulsive forces were $16.7 \%$ higher for the uninvolved limb. In general, there appears to be agreement among studies that the uninvolved limb tends to experience higher and more rapid loading following ACL reconstruction, during both single (previous studies) ${ }^{5-11}$ and multiple jump land-and-jump cycles (the current study). This shift in loading toward the uninvolved limb likely places greater demands on the uninvolved knee, as asymmetries in ground reaction forces appear to correlate with asymmetries in knee loading. ${ }^{22,23}$ In addition, previous studies have also found that athletes who have undergone ACL reconstruction demonstrate greater knee loading (e.g. increased knee extension moments) for their uninvolved limb during bilateral landing and jumping. ${ }^{6,10,11}$ These persistent kinetic asymmetries may increase risk of a secondary ACL injury ${ }^{24}$ and/or contribute to knee degenerative changes. ${ }^{11,25,26}$ As a result, there appears to be a need to explore novel rehabilitation approaches that could potentially more effectively target these persistent kinetic asymmetries. For instance, providing visual feedback related to side-to-side differences in limb loading during movement performance may be particularly effective for promoting inter-limb kinetic symmetry and minimizing maladaptive changes in an athlete's movement pattern following ACL reconstruction. ${ }^{27}$ It is also important to continue to examine factors that contribute to inter-limb kinetic asymmetry following ACL reconstruction (e.g. fear of re-injury, strength deficits, motor pattern adaptations). ${ }^{10,28,29}$

Although not the primary purpose of this study, it is interesting that athletes tended to make earlier initial contact with their uninvolved limb during landing (based on the sign of the average initial contact timing differences). While it should be noted that the $95 \%$ CIs all included zero, on average, initial contact occurred 4.4-6.5 ms earlier for the uninvolved limb across the five landings analyzed. Ford et al. ${ }^{19}$ examined initial contact limb preference during the initial landing phase of a drop vertical jump in 101 athletes who had undergone ACL reconstruction and found that $71.3 \%$ made initial contact first with their uninvolved limb. It appears that athletes who have undergone ACL reconstruction have a tendency to make initial contact with their uninvolved limb, prior to their involved limb, upon landing. Perhaps this reflects a movement strategy to reduce loading of the involved limb during bilateral landings.

The repetitive tuck jump task is a common plyometric training exercise for athletes. ${ }^{15}$ The results of this study indicate that athletes who have undergone ACL reconstruction may consistently offload their involved limb when performing repeated tuck jumps. Physical therapists, athletic trainers, and strength and conditioning coaches should consider this when prescribing the repetitive tuck jump task for athletes with a history of ACL reconstruction, as consistently offloading the involved limb and placing greater loads on the uninvolved limb may contribute to the development, or further development, of inter-limb neuromuscular asymmetries.

Although the findings from this study make a valuable contribution to an important body of literature, the study limitations need to be acknowledged. First, only the initial five land-and-jump cycles of the repetitive tuck jump task were examined; inter-limb symmetry could change as athletes complete additional cycles. In addition, the tuck jump task may not reflect the type of repetitive landing and jumping routinely performed in sports such as basketball. In-shoe kinetic sensors ${ }^{30}$ and inertial measurement units ${ }^{31}$ offer opportunities to examine inter-limb kinetic symmetry during landing and jumping under more game-like conditions. This study also did not include a comparison group of uninjured athletes. However, previous studies have already determined that athletes who have undergone ACL reconstruction demonstrate greater inter-limb kinetic asymmetry compared to athletes without a history of ACL reconstruction.

\section{CONCLUSION}

During performance of a repetitive tuck jump task, athletes who had undergone ACL reconstruction applied higher and more rapid loads to their uninvolved limb, compared to their involved limb. They also exhibited a tendency to make initial foot contact first with their uninvolved limb during landing. These inter-limb asymmetries may help to explain why athletes often sustain ACL injuries involving their previously uninjured limb upon returning to sport following ACL reconstruction. 


\section{DISCLOSURE}

\section{CONFLICTS OF INTEREST}

The authors have no conflicts of interest to disclose.

Submitted: November 24, 2020 CDT, Accepted: August 23, 2021 CDT

This is an open-access article distributed under the terms of the Creative Commons Attribution 4.0 International License (CCBY-NC-SA-4.0). View this license's legal deed at https://creativecommons.org/licenses/by-nc-sa/4.0 and legal code at https://creativecommons.org/licenses/by-nc-sa/4.0/legalcode for more information. 


\section{REFERENCES}

1. Gornitzky AL, Lott A, Yellin JL, Fabricant PD, Lawrence JT, Ganley TJ. Sport-specific yearly risk and incidence of anterior cruciate ligament tears in high school athletes: A systematic review and metaanalysis. Am J Sports Med. 2016;44(10):2716-2723. do i:10.1177/0363546515617742

2. Carey JL, Shea KG. AAOS Clinical Practice Guideline: Management of Anterior Cruciate Ligament Injuries Evidence-Based Guideline. J Am Acad Orthop Surg. 2015;23(5):e6-e8. doi:10.5435/jaao s-d-15-00095

3. Wiggins AJ, Grandhi RK, Schneider DK, Stanfield D, Webster KE, Myer GD. Risk of secondary injury in younger athletes after anterior cruciate ligament reconstruction. Am J Sports Med. 2016;44(7):1861-1876. doi:10.1177/036354651562155 $\underline{4}$

4. Paterno MV, Rauh MJ, Schmitt LC, Ford KR, Hewett TE. Incidence of second ACL injuries 2 years after primary ACL reconstruction and return to sport. Am J Sports Med. 2014;42(7):1567-1573. doi:10.1177/03635 46514530088

5. Baumgart C, Schubert M, Hoppe MW, Gokeler A, Freiwald J. Do ground reaction forces during unilateral and bilateral movements exhibit compensation strategies following ACL reconstruction? Knee Surg Sports Traumatol Arthrosc. 2017;25(5):1385-1394. doi:10.1007/s00167-015-362 $\underline{3-7}$

6. Ithurburn MP, Paterno MV, Thomas S, et al. Change in drop-landing mechanics over 2 years in young athletes after anterior cruciate ligament reconstruction. Am J Sports Med. 2019;47(11):2608-2616. doi:10.1177/03635465198646 $\underline{88}$

7. Paterno MV, Ford KR, Myer GD, Heyl R, Hewett TE. Limb asymmetry in landing and jumping 2 years following anterior cruciate ligament reconstruction. Clin J Sport Med. 2007;17(4):258-262. doi:10.1097/js m.0b013e31804c77ea

8. Paterno MV, Schmitt LC, Ford KR, Rauh MJ, Myer GD, Hewett TE. Effects of sex on compensatory landing strategies upon return to sport after anterior cruciate ligament reconstruction. J Orthop Sports Phys Ther. 2011;41(8):553-559. doi:10.2519/jospt.2011.359 1
9. Read PJ, Auliffe SM, Wilson MG, Graham-Smith P. Lower limb kinetic asymmetries in professional soccer players with and without anterior cruciate ligament reconstruction: nine months is not enough time to restore 'functional' symmetry or return to performance. Am J Sports Med. 2020;48(6):1365-1373. doi:10.1177/0363546520912218

10. Schmitt LC, Paterno MV, Ford KR, Myer GD, Hewett TE. Strength asymmetry and landing mechanics at return to sport after ACL reconstruction. Med Sci Sports Exerc. 2015;47(7):1426-1434. doi:10.1249/mss.00000000000 $\underline{00560}$

11. Shimizu T, Samaan MA, Tanaka MS, et al. Abnormal biomechanics at 6 months are associated with cartilage degeneration at 3 years after anterior cruciate ligament reconstruction. Arthroscopy. 2019;35(2):511-520. doi:10.1016/j.arthro.2018.07.033

12. Bakker R, Tomescu S, Brenneman E, Hangalur G, Laing A, Chandrashekar N. Effect of sagittal plane mechanics on ACL strain during jump landing. $J$ Orthop Res. 2016;34(9):1636-1644. doi:10.1002/jor.23 164

13. Hewett TE, Myer GD, Ford KR, et al. Biomechanical measures of neuromuscular control and valgus loading of the knee predict anterior cruciate ligament injury risk in female athletes: A prospective study. Am J Sports Med. 2005;33(4):492-501. doi:10.1177/0363546504269591

14. Leppänen M, Pasanen K, Kujala UM, et al. Stiff landings are associated with increased ACL injury risk in young female basketball and floorball players. Am J Sports Med. 2017;45(2):386-393. doi:10.1177/0363546 $\underline{516665810}$

15. Myer GD, Ford KR, Jensen BL, et al. The effects of plyometric vs. dynamic stabilization and balance training on power, balance, and landing force in female athletes. J Strength Cond Res. 2006;20(2):345-353.

16. Myer GD, Ford KR, Hewett TE. Tuck jump assessment for reducing anterior cruciate ligament injury risk. Athl Ther Today. 2008;13(5):39-44. doi:1 $\underline{0.1123 / \text { att.13.5.39 }}$

17. Sanders TL, Kremers HM, Bryan AJ, et al. Incidence of anterior cruciate ligament tears and reconstruction: A 21-year population-based study. Am J Sports Med. 2016;44(6):1502-1507. doi:10.1177/0 $\underline{363546516629944}$ 
18. Roos EM, Roos HP, Lohmander LS, Ekdahl C, Beynnon BD. Knee Injury and Osteoarthritis Outcome Score (KOOS)-development of a self-administered outcome measure. J Orthop Sports Phys Ther. 1998;28(2):88-96. doi:10.2519/jospt.1998.28.2.88

19. Ford KR, Schmitt LC, Hewett TE, Paterno MV. Identification of preferred landing leg in athletes previously injured and uninjured: A brief report. Clin Biomech. 2016;31:113-116. doi:10.1016/j.clinbiomec $\underline{\text { h.2015.09.020 }}$

20. Lim YY, Sterzing T, Teo CJY, et al. Between-limb asymmetry in kinetic and temporal characteristics during bilateral plyometric drop jumps from different heights. J Sport Sci. 2020;38(14):1605-1614. doi:10.10 $\underline{80 / 02640414.2020 .1752535}$

21. Robertson DGE, Dowling JJ. Design and responses of Butterworth and critically damped digital filters. $J$ Electromyogr Kinesiol. 2003;13(6):569-573. doi:10.101 6/s1050-6411(03)00080-4

22. Dai B, Butler RJ, Garrett WE, Queen RM. Using ground reaction force to predict knee kinetic asymmetry following anterior cruciate ligament reconstruction. Scand J Med Sci Sports. 2014;24(6):974-981. doi:10.1111/sms.12118

23. Nelson A, Koslakiewicz N, Almonroeder TG. Assessment of knee kinetic symmetry using force plate technology. J Sport Rehabil. 2018;27(6):609-611. doi:10.1123/jsr.2018-0002

24. Paterno MV, Schmitt LC, Ford KR, et al. Biomechanical measures during landing and postural stability predict second anterior cruciate ligament injury after anterior cruciate ligament reconstruction and return to sport. Am J Sports Med. 2010;38(10):1968-1978. doi:10.1177/03635465103760 $\underline{53}$
25. Erhart - Hledik JC, Chu CR, Asay JL, Favre J, Andriacchi TP. Longitudinal changes in the total knee joint moment after anterior cruciate ligament reconstruction correlate with cartilage thickness changes. J Orthop Res. 2019;37(7):1546-1554. doi:10.1 002/jor.24295

26. Shimizu T, Markes AR, Samaan MA, et al. Patients with abnormal limb kinetics at 6 months after anterior cruciate ligament reconstruction have an increased risk of persistent medial meniscal abnormality at 3 years. Orthop J Sports Med. 2020;8(1):232596711989524. doi:10.1177/2325967119 $\underline{895248}$

27. Chan M-S, Sigward SM. Loading behaviors do not matching loading abilities postanterior cruciate ligament reconstruction. Med Sci Sport Exerc. 2019;51(8):1626-1634. doi:10.1249/mss.00000000000 $\underline{01956}$

28. Gokeler A, Bisschop M, Myer GD, et al. Immersive virtual reality improves movement patterns in patients after ACL reconstruction: Implications for enhanced criteria-based return-to-sport rehabilitation. Knee Surg Sports Traumatol Arthrosc. 2016;24(7):2280-2286. doi:10.1007/s00167-014-337 $\underline{4-X}$

29. Trigsted SM, Cook DB, Pickett KA, CadmusBertram L, Dunn WR, Bell DR. Greater fear of reinjury is related to stiffened jump-landing biomechanics and muscle activation in women after ACL reconstruction. Knee Surg Sports Traumatol Arthrosc. 2018;26(12):3682-3689. doi:10.1007/s00167-018-495 $\underline{0-2}$

30. Peebles AT, Ford KR, Taylor JB, Hart JM, Sands LP, Queen RM. Using force sensing insoles to predict kinetic knee symmetry during a stop jump. J Biomech. 2019;95:109293. doi:10.1016/i.jbiomech.2019.07.037

31. Sigward SM, Chan M-SM, Lin PE. Characterizing knee loading asymmetry in individuals following anterior cruciate ligament reconstruction using inertial sensors. Gait Posture. 2016;49:114-119. doi:1 $\underline{0.1016 / \text { j.gaitpost.2016.06.021 }}$ 